\title{
University Library Charging Systems
}

The authors, who are respectively librarian and head of the circulation department at the University of Tennessee Library, considered their subject at the request of the editors of College and Research Libraries.

$\mathrm{T}$ HE PRESENT PAPER on university library charging systems took its rise largely from the following questions: What problems do the libraries face? What solutions have been adopted? What devices are still untried? What can be recommended to the libraries which are seeking relief? The authors have attempted to answer these questions, excepting the last, and suggest that a "line of reasoning" be substituted for specific recommendations.

A close analogy can be drawn between university libraries, with their currently inadequate charging systems, and the philosopher who was unable to do complete justice to his subject "tolerance" because there was a fly buzzing about the room. It is obvious to us that the philosopher might well have interrupted his lofty thinking long enough to swat the fly. Primarily, the purpose of this paper is to present a special plea for the case of university charging systems and to urge that serious attention be given to the correction of a small but troublesome problem which has already been tolerated too long. Although this article will attempt to list recent innovations in charging devices, it will by no means attempt to describe all the standard charging practices which have been long established and are well known to librarians.
No effort is being made to present here arguments for the desirability of reducing the amount of routine work connected with charging and discharging a book. This subject has been treated fully in the articles cited in the footnotes and can be summarized as: consideration of the borrower's time; lower costs through reduced clerical procedure; speeding up charging and discharging in order to make the file a more accurate record; and allowing circulation assistants more time for work of a professional nature.

The principal objection to charging systems in use at most university libraries is that they require too much writing on the part of the borrower. Where any very great consideration is given the reader, it usually has meant merely a transfer of his work to the staff. Of the two situations the latter is much to be preferred, but neither is very satisfactory. Ideally, there should be no writing necessary on the part of either reader or staff beyond the necessity of recording the reader's identity in connec-. tion with the withdrawal of a particular book. If the ideal of no writing cannot be attained, then the idea of the minimum should be pursued. Most college students seem to prefer signing their names to the alternative of constantly carrying a reader's card to which a particular number has been assigned. Except for those university libraries which are in large cities and which have a very large number'of students, where identification becomes more important, the librarian may logically consider the minimum amount of writing in connection with the circulation of a par- 
ticular book to be the borrower's signature and no writing at all on the part of the staff. Library science should be satisfied with nothing short of this simplified process, long since adopted by very small libraries, which actually requires merely the borrower's signature on the bookcard. The bookcard is filed variously-sometimes by class number, sometimes by borrower, and sometimes by date due. The file of books out is so small that any of the three circulation questions-where is the book, what books are overdue, and what books does a particular reader have-can be answered by running through the entire file without consuming enough time to label the system inadequate. The amount of circulation in a university library and the necessity of having a two-way check on the books automatically eliminate certain public library solutions of the problem, such as charging on microfilm, ${ }^{1}$ which might otherwise prove helpful.

The university circulation problem is further complicated by the fact that so many of the books are housed in the stacks, thus requiring the reader not only to identify himself with the circulation of a particular item but also making it necessary for him to describe the book by means of a call slip before it can even reach the point of being circulated. In some large libraries where a majority of the books circulated are shelved in the stacks, this problem is so great that it becomes the major one involved and has been attacked, quite properly, from the point of view that a call slip rather than a charging card constitutes the necessary minimum of writing. No better illustration can be given of this method of approach than that of Mr. Kilgour's solution to the problem by means of the keysort call slip, which eliminates the necessity

1 Pragan, Otto. "Photographic Charging of Books." Library Journal 68:1059-60, Dec. 15, 1943.

Shaw, Ralph R. "Reducing the Cost of the Lending Process." A.L.A. Bulletin 35:504-10, Oct. I, 1941. of any further writing on the part of the reader and requires no writing on the part of the staff. ${ }^{2}$ His solution has the further advantage of supplying the necessary twoway check on books out but requiring only one card to be filed. The key-sort system, however, breaks down when the reader decides to take a book from the open shelves or when he collects his own material from the stacks, which is often the case with upperclassmen, honors students, graduate students, faculty members, and even the library staff itself; for it is not very satisfactory to force the reader to fill out call slips for books he already has in hand. This is not a theoretical fault but a very real one and has constituted the basis for most of the criticism offered by the faculty and students where the system has been adopted. With the increasing growth of divisional reading rooms and the consequent increase in the number of books placed on open shelves, the key-sort system, while almost ideal for some large research libraries, has little to offer most university libraries. Some libraries may also find an answer to the problem in the use of business machine equipment, ${ }^{3}$ which affords a single file record with possibilities of sorting from any approach desired. Here again the call slip is used and is punched to indicate the date due and to obtain other information which is wanted. This is an expensive process, however, and would seem to be suitable only for the largest libraries.

Mr. Rogers, at the Columbia College Library, worked out a device ${ }^{4}$ whereby the key-sort principle is applied to the use of bookcards rather than call slips. Since this

\footnotetext{
${ }^{2}$ Kilgour, F. G. "A New Punched Card for Circulation Records." Library Journal 64:131-33, Feb. 15, I939. in Circulation Work." Library Journal 6r:903-05, Dec. 1. 1936.

Pratt, E. C. "International Business Machines" Use in Circulation Department, University of Florida Library." Library Journal 67:302-03, Apr. I, 1942. 4 Rogers, R. D. "A Charging Pocket Solution for Overdues." "Library Journal 66:1072-74, Dec. 15, I 94 I.
} 
allows for a one-card, two-way charging system employing a bookcard instead of a call slip, it is, theoretically at least, nearer the ideal minimum described above than anything which has yet come to the attention of the authors of this paper. But even this plan has certain drawbacks: since the bookcards are placed in key-sort pockets and then filed into the charging trays, the central file becomes approximately three times as large as would be the case if only the bookcard went into the file. For such a relatively small file as the one in Columbia College Library this is no great factor; but many university files are already so voluminous that several assistants are required to cover them adequately at busy periods, and anything which would triple their size becomes impracticable. Moreover, the number of cards in the main file is likely to grow as more and more libraries decide to consolidate all records, such as bindery, reading room, extended loans, lost books, and catalog department charges, with the regular loans to students. Experiences with the use of location cards in the catalog have not been very fortunate, and the desirable practice of keeping the open-shelf collections constantly changing, thus making location stamps on the catalog cards less desirable, tends to force even more cards into the main file.

\section{Tab Systems}

There are two types of tab systems which are in use in university libraries. One of these consists of placing protruding metal $t^{2} s^{5}$ on the tops of bookcards. The principal objections to this are that the tabs work loose and fall off, that they make reference to the file a very cumbersome process, and that they make filing an extremely tedious procedure. In the other tab system ${ }^{6}$ the tab forms a part of the card

5Helen, Sister. "Simplified Records for a College
Library." Library Journal 66:201-03, Mar. I, 1941.

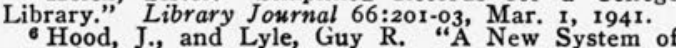

itself, with the date due printed on the tab. Since in this scheme the card involved is actually a call slip rather than a bookcard, it constitutes a substitute for the key-sort card and shares its advantages and disadvantages. The disadvantages are perhaps somewhat greater, however, as the date due is fixed when the call slip is filled out at the catalog. Should the book prove to be one requiring anything other than the regular loan, another call slip must be filled out in its place, and there is less flexibility generally in its successful adaptation to the varying loan lengths and reader categories.

Since none of the methods described has proved satisfactory for university libraries in general, the difficulty of making specific recommendations regarding the adoption of any circulation system now in existence should be apparent. One suggestion, however, can be offered: the first factor to be determined before deciding upon a new system is whether a call slip or a bookcard should be considered the desirable minimum; that is, whether most of the charges will be paged from the stacks or taken from the shelves (stack or open) by the reader. If a call slip must be made out for most of the books, the key-sort or punch-card type of system may be used, thus reducing the amount of writing for a majority of the borrowers at least. Many libraries, however, will find that the greater number of their charges are from open shelves or open stacks and that, consequently, a bookcard must be considered the desirable minimum. It is these libraries which are faced with a specific problem needing a rapid and satisfactory solution, i.e., how to get overdues out of a classed file. Actually, there is no real reason for clinging to the idea that

(Continued on page 57)

Book Charging for College Libraries." Library Journal 65:18-20, Jan. I, 1940.

Lynn, C.' L. "We Do It This Way." Catholic Library World 12 : 190-91, March 1941. 
that scholars often want to see first editions with the exact text as it went to press for the first printing.

Another point raised at Maine is "that the majority of books printed since 1870 will have a relatively short life-span compared to their predecessors." If, therefore, first editions are to be acquired, cannot writers, publishers, and librarians agree upon a better product of book making, to the end that at least a limited number of copies may be produced on durable paper for libraries and book collectors?

Practically all the collections reported have been secured for research purposes. Middlebury's reply regarding this, however, possibly indicates another aim: "Our main reason for collecting these modern authors is because they seem to us representative of the best today in modern American literature, and our Abernathy library is a library of American literature." Nearly all the libraries also are making additions to their collections.
A number of authors whose works are not represented in any New England collections were suggested by various librarians as worthy of being secured. Although only five librarians answered the question relating to this, the following writers were mentioned: Léonie Adams, Louis Adamic, James Truslow Adams, Hervey Allen, Sherwood Anderson, W. H. Auden, Charles A. Beard, Brian O. Donn-Byrne, Kenneth Burke, Van Wyck Brooks, Pearl S. Buck, Henry S. Canby, Mary Ellen Chase, Hart Crane, Cecil Day Lewis, Theodore Dreiser, E. M. Forster, Constance Holme, Robinson Jeffers, D. H. Lawrence, Ludwig Lewisohn, Katharine Mansfield, Lewis Mumford, George Jean Nathan, Donald C. Peattie, William Saroyan, the Sitwells, Upton Sinclair, Stephen Spender, Booth Tarkington, Carl Van Doren, Hendrik Willem van Loon, Wallace Stevens, Mary Webb, Edmund Wilson, A. Yvor Winters, Hugh Walpole, and William Carlos Williams.

\section{University Library Charging Systems}

\section{(Continued from page 53)}

there must even be a card involved, but the present authors lack the imagination to suggest a suitable substitute.

Since the problem is thus reduced to one of finding a suitable sorting device, possible solutions begin to present themselves; for example, a mere pencil mark placed on the bookcard would permit sorting by means of a photoelectric cell, or a small nonprotruding steel clip would allow for sorting by means of an electro-magnet. To these could be added other devices evolved from fundamental physical principles, but at this point the problem should be turned over to technicians who will probably have to be found outside the profession. The time for calling upon such technicians for assistance is long overdue. Some library supply houses have set up research bureaus, the interest and activity of which should be solicited. Expert council should be sought, and a satisfactory solution would be well worth the expenditure of the necessary funds. For this reason it is strongly urged that the Association of College and Reference Libraries take formal action, not to investigate the problem, but to seek a satisfactory solution by means of perfected mechanisms adaptable to the types of libraries involved. 